\title{
Responses of the Retinal Circulation to Systemic Autonomic Stimulation in Diabetes Mellitus
}

\author{
${ }^{*}$ L. P. LANIGAN, †CHARLES V. CLARK, J. ALLAWI, ${ }^{*}$ D. W. HILL, H. KEEN \\ London
}

\begin{abstract}
Summary
The retinal vessel calibre responses to systemic sympathetic stimulation, were studied in 22 randomly selected diabetic patients (mean age \pm SEM: $54.7 \pm 2.59$ years, range 25-73; 13 IDDM, 9 NIDDM; 4 females), using sustained isometric muscle contraction as the stimulus. At a different session the integrity of the autonomic nerve function in these diabetic patients was assessed using 3 standard tests of autonomic nerve function, based on cardiovascular reflexes. Diabetic patients with an intact autonomic nervous system: Group 1, $(n=11$, mean age: $54.9 \pm 4.55$ years, 7 IDDM 4 NIDDM) showed a mean arteriolar constriction of 9.2\% (SEM 2.89, p<0.01) and a mean venule constriction of $5.1 \%($ SEM 1.73, $<<0.02)$, for a mean rise in diastolic blood pressure of $23.7 \mathrm{mmHg}$ (SEM 2.19 range: 13-33). There were no significant mean retinal vessel responses however, in diabetics with autonomic dysfunction (Group 2): mean arteriolar constriction of $1.2 \%$ (SEM $1.38 \mathrm{p}>0.05$ ) and venule constriction of $2.1 \%$ (SEM 1.38, $\mathrm{p}>\mathbf{0 . 0 5}$ ); for a mean rise in diastolic blood pressure of $19.8 \mathrm{mmHg}$ (SEM 4.49, range: $2-50$ ). There was no correlation between the rise in diastolic blood pressure and the retinal arteriolar constriction in the 2 groups (Group 1: $r=0.45, p>0.1$ and Group 2: $r=0.56, p>0.05$ ). Duration, type and control of diabetes were not significantly different between the 2 groups. The severity of retinopathy was slightly worse in Group 2 compared to Group 1. These results point to an association between autonomic neuropathy and failure of regulation of retinal blood flow.
\end{abstract}

Autoregulation of the microcirculation is a well recognised phenomenon ${ }^{1}$ and has been demonstrated in the retinal circulation. ${ }^{2}$ Neurogenic, myogenic and humoral factors may be involved in the homeostatic maintenance of the retinal blood flow during changes in perfusion pressure, however, the definitive mechanism has not been established. Recently, a significant association has been demonstrated between retinal vessel calibre and systemic autonomic nerve stimulation, with consistent responses of the retinal vasculature to generalised sympathetic nerve stimulation. ${ }^{3}$ These results are particu- larly relevant to patients with diabetes, as diabetes mellitus is the commonest cause of autonomic neuropathy in the United Kingdom $;{ }^{4} 20-40 \%$ of diabetics have evidence of autonomic nerve dysfunction on initial presentation. ${ }^{5,6}$ Several studies have shown a significant association between autonomic nerve dysfunction and retinopathy in patients with diabetes mellitus..$^{7-9}$ Cardiovascular autonomic neuropathy has been demonstrated in $75 \%$ of diabetic patients with proliferative retinopathy ${ }^{7}$ and ocular autonomic neuropathy (involving the anterior segment of the eye) in $57 \%$ of this

Correspondence to: Research Department of Ophthalmology, Royal College of Surgeons of England, 35-43 Lincoln's Inn Fields, London WC2A 3PN.

From ${ }^{*}$ Research Department of Ophthalmology, Royal College of Surgeons of England; †Moorfields Eye Hospital and $\sim$ Unit of Metabolic Medicine, Guy's Hospital, London. 
group. ${ }^{8}$ The aim of this study was to assess the responses of the retinal circulation on systemic autonomic stimulation in patients with diabetes mellitus, using sustained handgrip as a test of sympathetic nerve function. ${ }^{10}$ The cardiovascular responses to sustained handgrip are reflex in nature ${ }^{11}$ and are thought to be initiated by stimuli from the exercising muscle. ${ }^{13}$ There is a rise in blood pressure, mediated partly by a heart rate dependent increase in cardiac output ${ }^{14}$ and partly by peripheral vasoconstriction mediated via alpha adrenergic receptors of the peripheral autonomic nervous system. ${ }^{12}$

\section{Patients and Methods}

Twenty-two diabetic patients, (mean \pm standard error of the mean (SEM) age: $54.7 \pm$ 2.59 years; range: $25-73$ years; 4 females) were included in the study following informed consent: 13 Insulin dependent diabetics (IDDM) (mean age $51.7 \pm 3.97$ years) and 9 non insulin dependent diabetics (NIDDM) (mean age 59.1 \pm 2.23 years). These patients were subdivided into two equal groups based on the results of autonomic function assessment as defined by Ewing et al., 1986 (Table I). ${ }^{15}$ Group 1 consisted of 11 patients with no evidence of autonomic nerve dysfunction (mean age 54.9 \pm 4.55 years): 7 IDDM (mean age $51.0 \pm$ 6.66 years) and 4 NIDDM (mean age $61.8 \pm$ 3.12 years); Group 2 comprised 11 patients with autonomic dysfunction (mean age 54.5 \pm 2.77 years), 6 IDDM (mean age $52.5 \pm$ 4.48 years) and 5 NIDDM (mean age $57.0 \pm$ 3.08 years). The mean duration of diabetes in this series was $12.2 \pm 1.83$ years; mean duration of diabetes in patients with autonomic dysfunction (Group 2: $13.2 \pm 2.77$ years) was not significantly different from diabetics with no evidence of autonomic dysfunction (Group 1: $11.3 \pm 2.50$ years, $0.1>\mathrm{p}>0.05$ ). Long term control of diabetes was assessed by glycosylated haemoglobin estimation in all subjects.

Autonomic nerve function and retinal vasculature responses to autonomic stimulation were assessed by the following methods:

\section{Autonomic Nerve Function:}

(i) Immediate heart rate response to standing. ${ }^{15}$ The heart rate was determined from a continuously recorded electrocardiograph, and the ratio of the longest $\mathrm{R}-\mathrm{R}$ interval around the 30th beat after standing to the shortest R-R interval around the 15 th beat calculated (30:15 ratio).

(ii) Systolic blood pressure response to standing. ${ }^{15}$ This test is performed by measuring the blood pressure in the supine position and after 2 minutes standing. The difference in systolic blood pressure is taken as the measure of the postural blood pressure change.

(iii) Diastolic blood pressure response to sustained handgrip. ${ }^{10}$

3 baseline blood pressures were recorded from the non-exercising arm. Each patient then performed a sustained handgrip using the dominant arm, at $33 \%$ maximum voluntary contraction for 2.5 minutes. A blood pressure read-

Table I Normal, borderline and abnormal values for cardiovascular autonomic function tests

(DJ Ewing et al, 1986).

NORMAL BORDERLINE ABNORMAL

Immediate heart rate response to standing ( $30: 15$ ratio).

$$
\begin{array}{lll}
\geqslant 1.04 & 1.01-1.03 & \leqslant 1.00 \\
\leqslant 10 \mathrm{mmHg} & 11-29 \mathrm{mmHg} & \geqslant 30 \mathrm{mmHg} \\
\geqslant 16 \mathrm{mmHg} & 11-15 \mathrm{mmHg} & \leqslant 10 \mathrm{mmHg}
\end{array}
$$$$
\text { Blood pressure response to }
$$$$
\text { standing (fall in systolic BP) }
$$

Blood pressure response to sustained handgrip (rise in Diastolic BP) 
ing was taken just before release of the handgrip. The rise in diastolic blood pressure to sustained handgrip was taken as the difference between the diastolic blood pressure after 2.5 minutes of sustained contraction and the mean baseline diastolic blood pressure.

\section{Retinal Circulation Responses to Systemic Autonomic Stimulation}

Each patient was studied seated at the fundus camera: one pupil was dilated (whichever was preferred by the subject) with $\mathrm{g}$. tropicamide $1 \%$ and $\mathrm{g}$. phenylephrine $10 \%$. All photographs were taken by the same observer using a wide angle Canon camera (CF 60-S), which was triggered during the diastolic phase of the pulse cycle. Five photographs were taken in quick succession, at approximately one second intervals at each phase. Baseline photographs were taken, followed by three baseline blood pressure measurements recorded from the non-exercising arm using an automatic sphygmomanometer (COPAL - UA 231). The subject was then instructed to perform three maximum handgrip contractions using the dominant arm to establish their maximum voluntary contraction (MVC). A laboratory-built strain gauge dynamometer with continuous chart recording was used with an adjustable audible alarm, set to alarm below $33 \%$ of each patient's MVC. The patient was then instructed to perform a sustained handgrip at $33 \%$ MVC for 2-2.5 minutes; three blood pressure measurements were recorded at 0.5 , 1.5 and 2.5 minutes and three phases of fundus photographs were taken at 1,2 and 2.5 minutes. On recovery one final phase of fundus photographs and one blood pressure reading were taken at five minutes after release of handgrip contraction. All photographs were recorded on Ilford FP4 film, with a red free filter and developed in PQ Universal $(1+19)$ for 12 minutes at $20^{\circ} \mathrm{C}$ with sensitometric control. ${ }^{16}$

All films were analysed using the Quantimet 800 Image analyser (Cambridge Instruments). This technique has been established in the department (R.C.S). ${ }^{16}$ Ten to eighteen suitable vessel sites were selected in each subject comprising similar numbers of arterioles and venules nominally within the calibre range: $64-174 \mu \mathrm{m}$, calculated on the basis of the Gullstrand Schematic Eye. A typical fundus photograph illustrating sites of measurement is shown in Figure 1.

Vessel calibres at these sites were measured and the means, standard error of the means (SEM) and one way analysis of variance (ANOV) for each site, within replications and between the phases, were calculated. Percentage change in mean retinal vessel calibre between phase 1 (pre-test) and phase 4 (following 2.5 minutes of handgrip) for each subject was calculated; significance was assessed by the student $t$ test for paired data (2 tailed)

Least significant differences between phase means, at those sites where a significant ANOV was demonstrated, were calculated by applying the ' $\mathrm{t}$ ' distribution to the within phase replication variance. ${ }^{16}$

\section{Results:}

The results of autonomic function assessment and retinal vessel responses to systemic autonomic stimulation for each individual patient in Groups 1 and 2 are shown in Tables II and III respectively.

\section{Group 1: Diabetic patients with normal autonomic nerve function}

In response to sustained handgrip, arteriolar calibre (mean \pm SEM) decreased by $9.2 \pm$ $2.89 \%, \mathrm{p}<0.01$ and venule calibre decreased by $5.1 \pm 1.73 \%, \mathrm{p}<0.02$; diastolic blood pressure increased by $23.7 \pm 2.19 \mathrm{mmHg}$ (range: $13-33 \mathrm{mmHg}$ ). Mean variations in retinal vessel calibre and diastolic blood pressure for each subject in Group 1 are shown in Figure 2.

No significant correlation was present between the elevation of diastolic blood pressure and retinal vessel constriction (Table III, $\mathrm{r}=0.45 ; \mathrm{p}>0.1$.)

\section{ii. Group 2: Diabetic patients with autonomic} dysfunction.

In response to sustained handgrip, arteriolar calibre decreased by $1.2 \pm 1.38 \%$ and venule calibre decreased by $2.1 \pm 1.38 \%$, neither change being significant at the 5\% level. Diastolic blood pressure increased by $19.8 \pm$ 


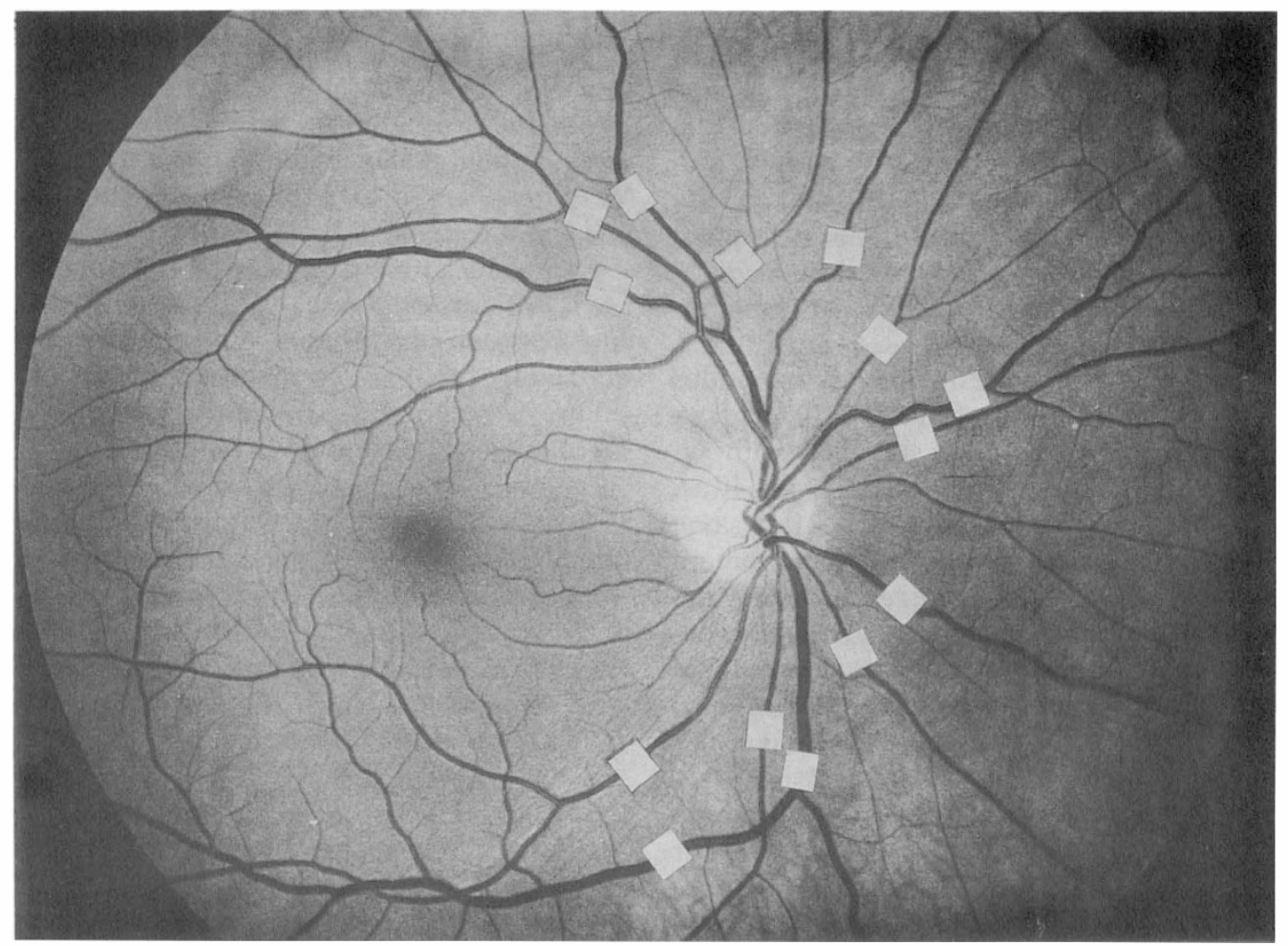

Fig. 1. Typical fundus photograph with selected sites of measurement.

Table II Group 2: Diabetics with autonomic dysfunction

\begin{tabular}{|c|c|c|c|c|c|c|c|c|c|c|c|}
\hline \multirow[t]{2}{*}{$\begin{array}{l}\text { Subj. } \\
\text { no.. }\end{array}$} & \multirow[t]{2}{*}{$\operatorname{sex}$} & \multirow[t]{2}{*}{ age } & \multirow[t]{2}{*}{$\begin{array}{l}\text { diab } \\
\text { type }\end{array}$} & \multirow[t]{2}{*}{$\begin{array}{l}\text { duration } \\
\text { of diab. }\end{array}$} & \multirow[t]{2}{*}{$\begin{array}{l}\text { Retinop. } \\
\text { grade }\end{array}$} & \multicolumn{3}{|c|}{$\begin{array}{l}\text { autonomic nerve } \\
\text { function tests }\end{array}$} & \multirow{2}{*}{$\begin{array}{l}\text { no. of } \\
\text { abn/ } \\
\text { border- } \\
\text { line tests } \\
\text { G }\end{array}$} & \multicolumn{2}{|c|}{$\begin{array}{c}\text { mean retinal } \\
\text { vessel change } \%\end{array}$} \\
\hline & & & & & & $30: 15$ & $\begin{array}{l}S B P \\
L / S\end{array}$ & $D B P H G$ & & Art & Ven \\
\hline 1 & $\mathbf{M}$ & 54 & IDDM & $29 y r s$ & 1 & 1.03 & -40 & +7 & $2 / * 1$ & -1 & -8 \\
\hline 2 & M & 67 & NIDDM & $25 \mathrm{yrs}$ & 2 & 1.00 & 0 & +12 & $1 / * 1$ & -3 & -8 \\
\hline 3 & M & 60 & NIDDM & $5 y r s$ & 2 & 1.06 & -30 & +18 & 1 & +2 & +0.3 \\
\hline 4 & $\mathrm{~F}$ & 56 & NIDDM & $6 y r s$ & 2 & 0.85 & +29 & +12 & $1 /{ }^{*} 1$ & -4 & -4 \\
\hline 5 & $\mathrm{~F}$ & 53 & NIDDM & $11 \mathrm{yrs}$ & 3 & 1.08 & -20 & +2 & $1 /{ }^{*} 1$ & -11 & -8 \\
\hline 6 & $\mathbf{M}$ & 49 & NIDDM & 9yrs & 0 & 1.06 & -35 & +37 & 1 & +2 & +2 \\
\hline 7 & $\mathbf{M}$ & 71 & IDDM & $12 \mathrm{yrs}$ & 2 & 1.00 & -42 & +23 & 2 & +7 & 0 \\
\hline 8 & M & 56 & IDDM & $1 \mathrm{yr}$ & 0 & 0.83 & +25 & +17 & 1 & -3 & -0.2 \\
\hline 9 & M & 42 & IDDM & $25 y r s$ & 3 & 1.00 & 0 & +34 & 1 & -2 & -4 \\
\hline 10 & $\mathbf{M}$ & 41 & IDDM & $9 y r s$ & 1 & 1.00 & -20 & +50 & $1 / * 1$ & +2 & +2 \\
\hline 11 & $\mathbf{M}$ & 51 & IDDM & $13 y r s$ & 2 & 0.95 & -30 & +6 & 3 & -2 & +2 \\
\hline
\end{tabular}

*: borderline results for autonomic nerve function tests.

SBP L/S: postural change in systolic BP from lying to standing

DBP HG : rise in diastolic blood pressure to sustained handgrip. 
Table III Group 1: Diabetics with intact autonomic nervous system

\begin{tabular}{|c|c|c|c|c|c|c|c|c|c|c|c|}
\hline \multirow[t]{2}{*}{$\begin{array}{l}\text { Subj. } \\
\text { no. }\end{array}$} & \multirow[t]{2}{*}{$\operatorname{sex}$} & \multirow[t]{2}{*}{ age } & \multirow[t]{2}{*}{$\begin{array}{l}\text { diab } \\
\text { type }\end{array}$} & \multirow[t]{2}{*}{$\begin{array}{l}\text { duration } \\
\text { of diab. }\end{array}$} & \multirow[t]{2}{*}{$\begin{array}{l}\text { Retinop. } \\
\text { grade }\end{array}$} & \multicolumn{3}{|c|}{$\begin{array}{l}\text { autonomic nerve } \\
\text { function tests }\end{array}$} & \multirow{2}{*}{$\begin{array}{l}\text { no. of } \\
\text { abn/ } \\
\text { border- } \\
\text { line tests }\end{array}$} & \multicolumn{2}{|c|}{$\begin{array}{l}\text { mean } \% \text { retinal } \\
\text { vessel change }\end{array}$} \\
\hline & & & & & & $30: 15$ & $\begin{array}{l}S B P \\
L / S\end{array}$ & $D B P H G$ & & Art & Ven \\
\hline 1 & $\mathbf{M}$ & 71 & NIDDM & $7 \mathrm{yrs}$ & 0 & 1.18 & +20 & +15 & $* 1$ & -19 & -6 \\
\hline 2 & M & 58 & NIDDM & $4 y r s$ & 0 & 1.19 & +8 & +28 & 0 & -4 & -3 \\
\hline 3 & M & 60 & NIDDM & $2 \mathrm{yrs}$ & 0 & 1.18 & -10 & +20 & 0 & -9 & -3 \\
\hline 4 & M & 58 & NIDDM & $2 \mathrm{yrs}$ & 0 & 1.17 & -15 & +30 & $* 1$ & -4 & -2 \\
\hline 5 & M & 67 & IDDM & $25 \mathrm{yrs}$ & 2 & 1.18 & -4 & +33 & 0 & -1 & -5 \\
\hline 6 & M & 60 & IDDM & $14 \mathrm{yrs}$ & 0 & 1.23 & -5 & +29 & 0 & -8 & -4 \\
\hline 7 & $\mathrm{~F}$ & 55 & IDDM & $17 \mathrm{yrs}$ & 1 & 1.23 & -4 & +29 & 0 & -6 & -3 \\
\hline 8 & M & 25 & IDDM & $25 \mathrm{yrs}$ & 0 & 1.20 & -6 & +17 & 0 & -33 & -22 \\
\hline 9 & M & 73 & IDDM & $6 y r s$ & 1 & 1.15 & +2 & +17 & 0 & +2 & -3 \\
\hline 10 & $\mathbf{M}$ & 43 & IDDM & 9yrs & 1 & 1.19 & -5 & +30 & 0 & -10 & -3 \\
\hline 11 & M & 34 & IDDM & $13 y r s$ & 3 & 1.16 & +2 & +13 & ${ }^{* 1}$ & -9 & -2 \\
\hline
\end{tabular}

*: borderline results for autonomic nerve function tests

SBP L/S: postural change in systolic blood pressure from lying to standing

DBP HG : rise in diastolic blood pressure to sustain handgrip

ARTERIES
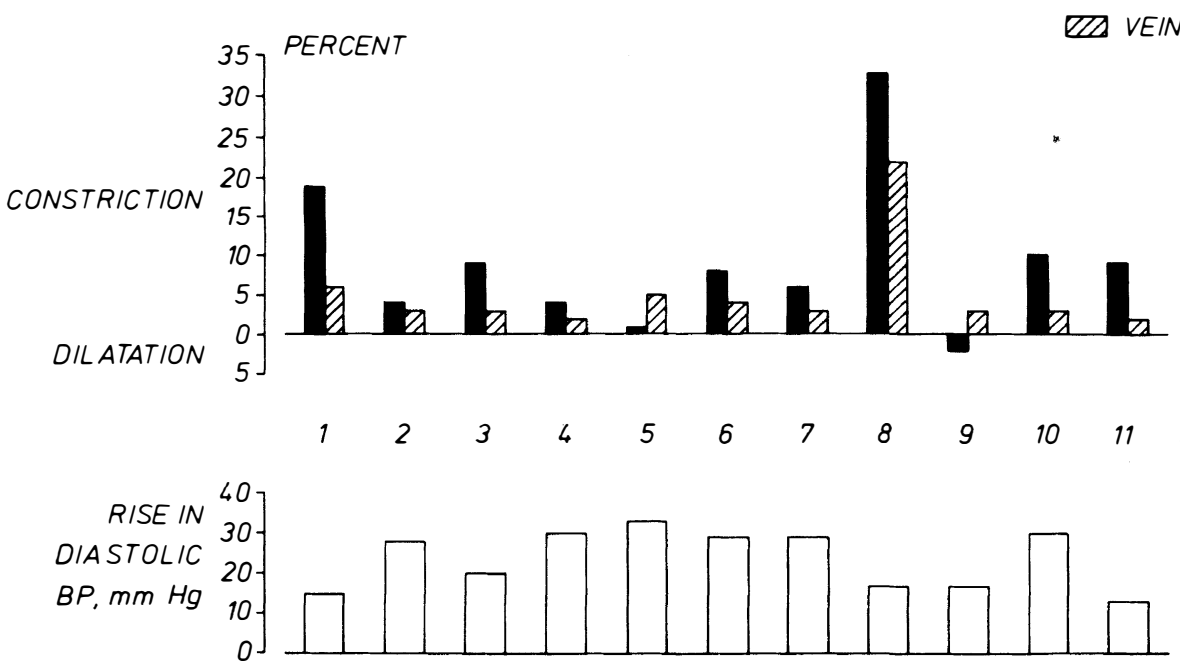

Fig. 2 Change in mean retinal vessel calibre and the rise in diastolic blood pressure for each diabetic in Group 1, from control to 2.5 minutes handgrip contraction.

$4.49 \mathrm{mmHg}$ (range: $2-50 \mathrm{mmHg}$ ). Mean variations in retinal vessel calibre and diastolic blood pressure for each subject in Group 2 are shown in Figure 3.

No significant correlation was present between the elevation in diastolic blood pressure and retinal vessel constriction (Table II, $\mathrm{r}=0.56 ; 0.1>\mathrm{p}>0.05)$.
Mean arteriolar calibre changes in response to sustained handgrip were significantly lower in diabetics with autonomic dysfunction than in those with intact autonomic nerve function ( $\mathrm{t}$ test difference of means, $0.05>p>0.02$ ). There was no significant difference in venule calibre changes between the 2 Groups $(\mathrm{p}>0.1)$. 


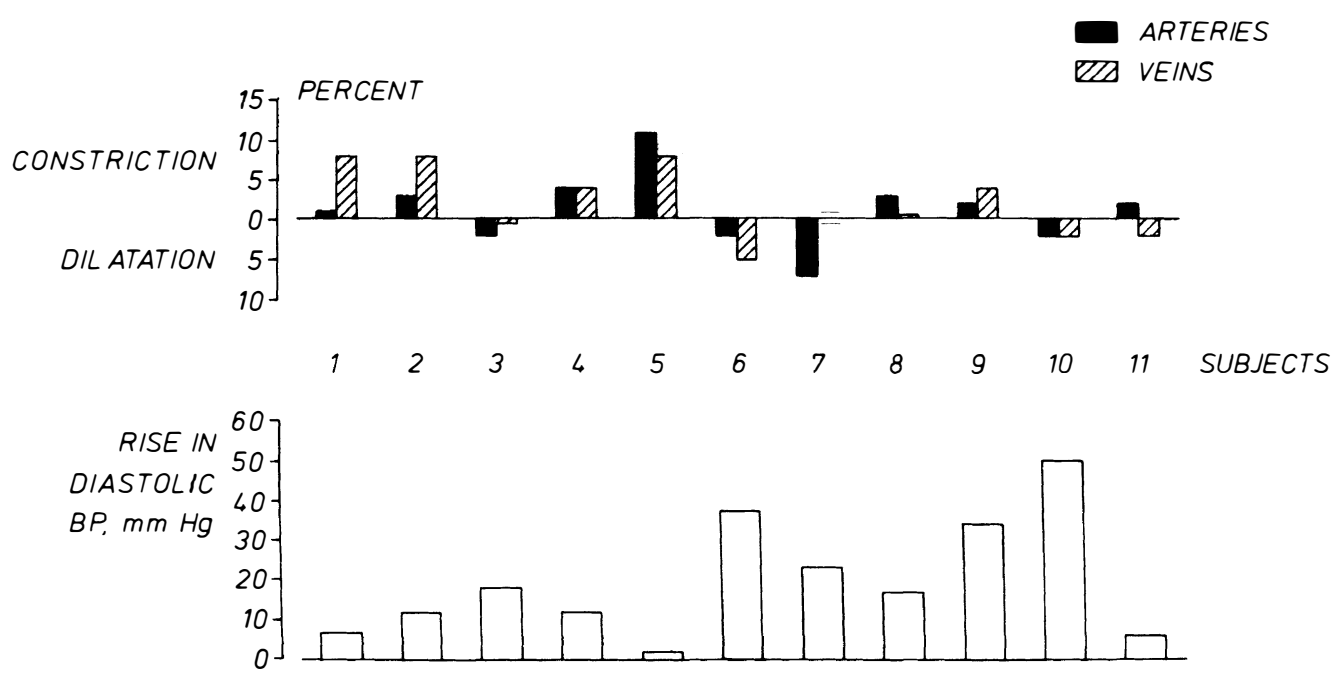

Fig. 3 Change in mean retinal vessel calibre and the rise in diastolic blood pressure for each diabetic in Group 2, from control to 2.5 minutes handgrip contraction.

iii. Individual results:

Background variance is an inevitable feature of a multistage measurement process as used in this study to assess retinal vessel calibre changes: this varies from site to site depending largely upon the clarity of the image; the use of replication photographs permits an evaluation of the variance. In all, 90 arterial sites in Group 1 and 88 in Group 2 were measured and the spread of the within replication variances taken from the individual site analyses of variances examined. One subject No.4, Group 2 (mean calibre change: arterial $-4 \%$, venous $-4 \%$ ) had markedly less consistent measurements over all 10 sites, due to photographic difficulties and was excluded from this calculation. Of the remaining 21 subjects the individual site within replication variances, transposed in terms of percent calibre change, gave a cumulative frequency distribution of the least significant differences (LSD) between the phase means, at the $95 \%$ level, shown in Table IV. The cumulative frequency distributions for the two groups of diabetic subjects (with exclusion of subject 4, Group 2) were very similar.

These results indicated the need in this study for relatively large calibre changes in order to attain significant individual differences, however significant calibre constrictions occurred between phase 1 (control) and phase 4 (last photographs during handgrip) in 25 of the 90 sites in Group 1, but only 8 of the 88 sites in Group 2, thus confirming the impression of reduced arteriolar response in Group 2 which is conveyed by the subject mean arteriolar calibre changes (Tables II, III).

\section{iv. Handgrip performance.}

The subject maximum handgrip tests showed a similar strength of grip in both groups (Group 1, mean 45.2, standard deviation (SD) \pm 12.8 ; Group 2, mean 57.0, SD \pm 15.1 , arbitrary units, strain igauge recording). The time weighted mean grip force during the test was well maintained in both groups, being $+11.5 \%, \mathrm{SD} \pm 7.2$ and $+10.7 \%, \mathrm{SF} \pm 12.6$ in groups 1 and 2 respectively, above the target level (33\% MVC). In no instance did the time weighted mean fall significantly below the target level, the lowest level being $-1 \%$.

Table IV Least Significant Differences at $95 \%$ Probability Level

Individual arteriolar sites

\begin{tabular}{cc}
\hline Difference interval $\%$ & cumulative frequency $\%$ \\
\hline $1-10$ & 46 \\
$11-20$ & 77 \\
$>20$ & 100 \\
\hline
\end{tabular}




\section{v. Diabetic retinopathy.}

The incidence of diabetic retinopathy was determined by ophthalmoscopy at the time of pupil dilatation for calibre studies, assisted by inspection of the calibre measurement photographs; results were expressed in 4 categories:

0 ... no retinopathy

1 ... mild background retinopathy $(<10$ haemorrages)

2 ... severe background retinopathy $(>10$ haemorrages and/or exudates

3 ... Proliferative retinopathy.

Findings for the two groups are shown in Table V. The numbers are too small for statistical testing but the trend suggests a greater severity in Group 2.

\section{vi. Glycosylated haemoglobin}

There were no significant differences in glycosylated haemoglobin (mean \pm SEM) between patients in Group $1(8.0 \pm 0.76 \%)$ and Group $2(9.3 \pm 0.55 \%)$.

\section{Discussion}

The retinal vessels have an intrinsic ability to dilate or constrict in order to maintain constant blood flow to the retina. Sustained handgrip causes a significant elevation in diastolic blood pressure (a response mediated by the sympathetic nervous system), implying a concomitant increase in retinal perfusion. Retinal vessel constriction occurs in normal subjects in response to the systemic sympathetic stimulation precipitated by this stimulus. ${ }^{3}$ Retinal vascular responses to autonomic stimulation in diabetics with intact autonomic function (within the limits of sensitivity of these tests) were similar to those of a group of 11 normal subjects of similar age (unpublished observations; mean age $53.9 \pm 2.55$ years; range: $42-$ $65)$, showing an arteriolar constriction of

Table V Prevalence of Diabetic Retinopathy

\begin{tabular}{ccc}
\hline Category & Group 1 & Group 2 \\
\hline 0 & 6 & 2 \\
1 & 3 & 2 \\
2 & 1 & 5 \\
3 & 1 & 2 \\
\hline
\end{tabular}

7.4\% (Group 1: 9.2\%); and venous constriction of 3.8\% (Group 2: $5.1 \%$ ). By contrast, in Group 2 diabetic patients with autonomic dysfunction, the mean arteriolar constriction $(1.2 \%)$ was significantly lower than in Group 1 (' $\mathrm{t}$ ' test, difference of means, 2.49, $0.05>p>0.02)$, though the performance in the handgrip test was similar in the two groups. The venous response was also reduced to a constriction of $2.4 \%$. Neither of these group 2 mean changes represents a significant departure from the baseline values; though on ANOV occasional arteriolar sites showed significant constriction ( 8 out of 88 sites as compared to Group 1, 25 out of 90). These results indicate a very considerable loss of retinal vascular response in Group 2, the recorded changes being due largely to random error, except perhaps in subject No. 5.

There was no correlation between elevation of diastolic blood pressure and the degree of retinal vessel constriction in either group or in our unpublished study of normal subjects of similar age range (quoted above), who sustained a mean diastolic blood pressure rise of $21.3 \pm 1.70 \mathrm{mmHg}$, not significantly different from groups 1 and 2 . In Group 2 diabetics with autonomic dysfunction, there is a dissociation of effects with virtual loss of the retinal vessel response, but a similar mean diastolic bloód pressure rise to that in Group 1; though the variance of Group 2 is significantly greater ( $F$ ratio 4.16, $0.025>p>0.01$ ) indicating a greater spread of blood pressure responses. These two factors, lack of correlation between blood pressure and vessel constriction and dissociation of effects in autonomic neuropathy are evidence for independent responses of blood pressure and retinal vessels to a generalised sympathetic stimulus. The relationship of diastolic blood pressure and retinal arteriolar calibre response is seen graphically in Figure 4.

An association has already been established between proliferative retinopathy and autonomic nerve function in diabetes. ${ }^{7-9}$ The present study includes only 3 patients with proliferative retinopathy, too small a group for valid comment upon this association; although it is interesting to note (Table V) that of 22 randomly selected diabetic 


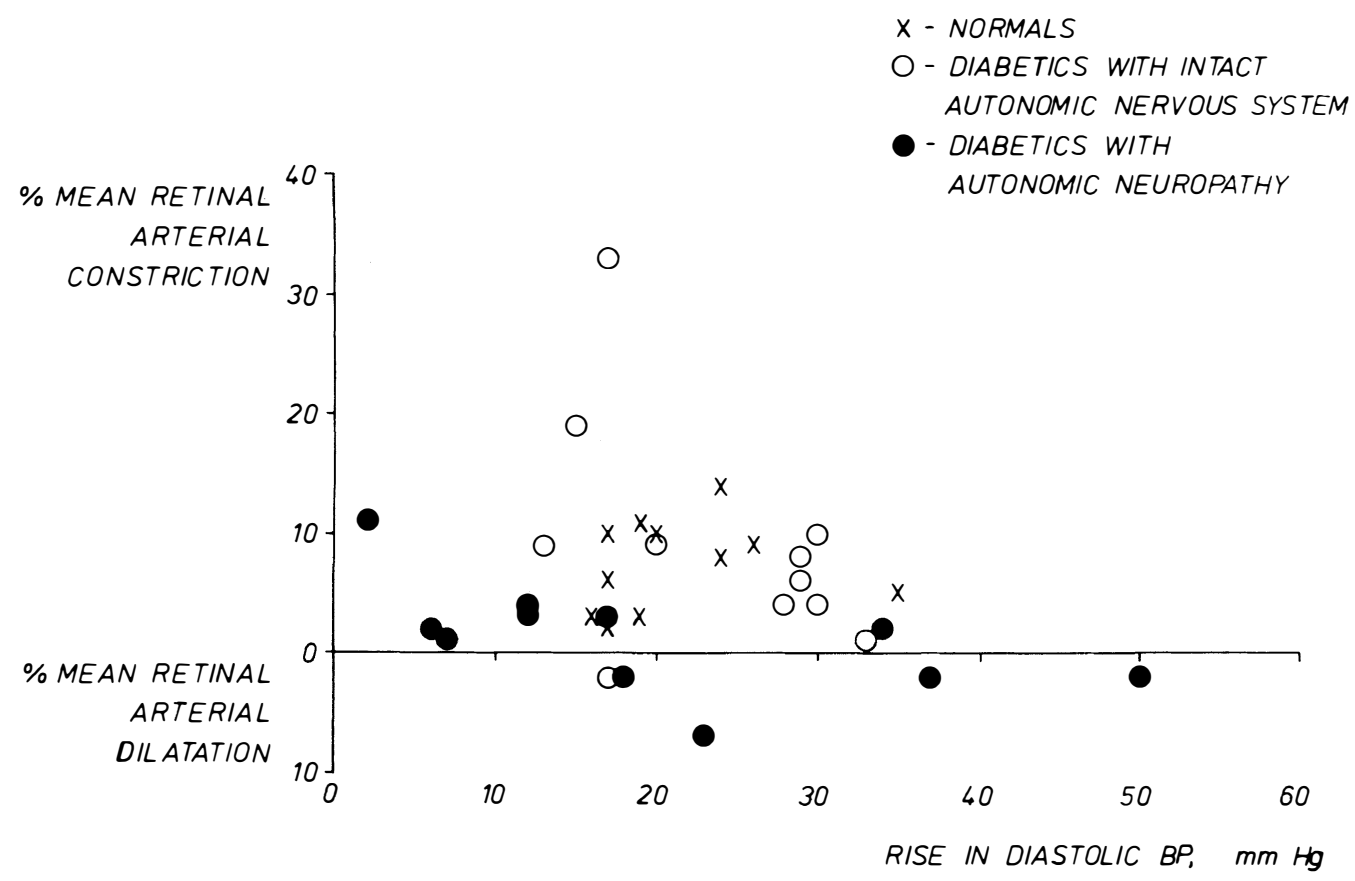

Fig. 4. This scattergram shows the relationship between diastolic blood pressure rise and mean retinal arteriolar constriction during sustained handgrip contraction in 3 groups of subjects: diabetics without demonstrable autonomic neuropathy (Group 1), diabetics with autonomic neuropathy (Group 2) and normal subjects of similar age range. Note the dissociation between the two responses, the greater variability of arteriolar responses in Group 1 as compared to the normal and the virtually absent vessel calibre response in Group 2.

patients, 6 of the 11 subjects with intact autonomic function (Group 1) had no evidence of retinopathy, compared to only 2 of the 11 subjects with autonomic dysfunction (Group 2); furthermore severe background retinopathy was present in only 2 subjects of the first group as compared to seven of the second, which supports the general association between autonomic neuropathy and diabetic retinopathy.

Autonomic neuropathy may interfere with autoregulatory mechanisms. ${ }^{18,19}$ Several studies have demonstrated abnormalities in the retinal circulation in diabetic patients. ${ }^{20-25}$ Rhie et al $^{21}$. showed that retinal vascular reactivity to norepinephrine and angiotensin II in diabetics with retinopathy was abnormal compared to control subjects and diabetics without retinopathy, and Sinclair et al. ${ }^{26}$ concluded that retinal vascular autoregulation decreases as diabetic re- tinopathy increases, with complete loss of autoregulation in patients with proliferative retinopathy.

Duration, type and control of diabetes were not significantly different between the two groups in the present study and therefore the results cannot be explained as a direct manifestation of diabetic severity. The only significant difference between these otherwise equivalent groups of diabetic patients was the integrity of the autonomic nerve function.

This study establishes, that in response to sustained isometric muscle contraction, there is a dissociated loss of retinal vascular reactivity, which occurs in association with clinical evidence of autonomic neuropathy. The retinal vascular response is not linked to the rise in diastolic blood pressure which occurs during the isometric muscle contraction and its mechanism requires further investigation. 
We thank the patients who took part in this study, K. Brophy SRN, Research Nurse and the Nursing Staff, Unit of Metabolic Medicine, Guys Hospital for their assistance. We thank Dr DJ Ewing, University of Edinburgh, for advice relating to autonomic nerve function assessment. LP Lanigan holds a Smith \& Nephew Fellowship in Ophthalmology. The project was supported by a grant from the Royal National Institute for the Blind.

\section{References}

1 Johnson PC: Review of previous studies and current theories of autoregulation. Circ Res 1964, 15 (suppl 1): 2.

2 Riva CE, Sinclair SH, Grunwald JE: Autoregulation of the retinal circulation in response to decrease in perfusion pressure. Invest Ophthalmol Vis Sci 1981, 21: 43-8.

${ }^{3}$ Lanigan LP, Clark CV, Hill DW: Retinal circulation responses to systemic autonomic nerve stimulation. Eye 1988 2: 412-7.

${ }^{4}$ Watkins PJ and Edmonds ME: Clinical presentation of diabetic autonomic failure. In Bannister $\mathrm{R}$ ed. Autonomic failure. Oxford: Oxford Univ Press 1983: 332.

5 Sharpey-Shafer EP and Taylor PJ: Absent circulatory reflexes in diabetic neuritis. Lancet 1960, i: 559-62.

${ }^{6}$ Hilsted J and Jensen SB: A simple test for autonomic neuropathy in juvenile diabetics. Acta Med Scand 1979, 205: 385-7.

${ }^{7}$ Clark CV: Autonomic neuropathy in proliferative diabetic retinopathy. Eye 1987, 1: 496-9.

${ }^{8}$ Clark CV: Ocular autonomic nerve function in proliferative diabetic retinopathy. Eye 1988, 2: 96-101.

${ }^{9}$ Smith SE, Smith SA, Brown PM: Cardiac autonomic dysfunction in patients with diabetic retinopathy. Diabetologia 1981, 21: 525-8.

${ }^{10}$ Ewing DJ, Irving JB, Kerr F, Wildsmith JAW, Clarke BF: Cardiovascular responses to sustained handgrip in normal subjects and in patients with diabetes mellitus. Clin Sci Mol Med 1974, 46: 295-306.

11 Coote JH, Hilton SM, Perez-Gonzalez JF: The reflex nature of the pressor response to muscular exercise. J Physiol 1971, 215: 789-804.

12 Freyschuss U, Cardiovascular adjustments to somatometer activation. Acta Physiol Scand 1970, Suppl 342.

13 Donald KW, Lind AR, McNicholl GW, Humphreys PW, Taylor SH, Staunton HP: Car- diovascular responses to sustained (static) contractions. Circ Res 1967, 20 (suppl 1): 1530.

${ }^{14}$ Lind AR, Taylor SF, Humphreys PW, Kennelly $\mathrm{BM}$, Donald KW: The circulatory effects of sustained voluntary muscle contraction. Clin sci 1964, 27: 229-44.

${ }^{15}$ Ewing DJ and Clarke BF: Autonomic neuropathy: Its diagnosis and prognosis. In Clinics in endocrinology and metabolism. Watkins PJ ed WB Saunders company, London 1986, 15(4): 855-88.

${ }^{16}$ Hill DW and Crabtree A: Vascular calibres. Trans Ophthalmol Soc UK 1984, 104: 107.

${ }^{17}$ Elementary statistical methods 3rd edn, Wetherill GB, Chapman and Hall, London, 1982: 272.

18 Grover-Johnson N and Pearson J: Deficient vascular innervation in familial dysautonomia, an explanation for vasomotor instability. Neuropath Appl Neurobiol 1976, 2: 217-24.

${ }_{19}$ Grover-Johnson N and Kim GE: Ultrastructural evidence of a decrease in autonomic nerves which innervate small blood vessels in diabetics. J Neuropath Exp Neurol 1976; 35: 336.

${ }^{20}$ Osei K, Fields PG, Cataland S, Craig EL, George JM, O'Dorsio TM. Abnormal retinal artery responses to stress in patients with Type 1 diabetes. Am J Med 1985, 78: 595-601.

${ }^{21}$ Rhie FH, Chriestlieb AR Sender T et al.: Retinal vascular reactivity to norepinephrine and angiotensin II in normals and diabetics. Diabetes 1982, 31: 1056-60.

22 Kohner EM: The problems of retinal blood flow in diabetics. Diabetes 1976 25(suppl 12): 839844.

23 Yoshida A, Feke GT, Morales-Stopello J et al.: Retinal blood flow alterations during progression of diabetic retinopathy. Arch Ophthalmol 1983, 101: 225-7.

${ }^{24}$ Chriestlieb AR, Janka H, Kraus B, Gleason RE: Icasus-Cabral EA, Aiello LM, Cabral BV, Solano A: Vascular reactivity to Angiotensin II and to norepinephrine in diabetic subjects. Diabetes 1976, 25: 268-74.

25 Blair NP, Feke GT, Morales-Stopello J, Riva CE, Goger DG, Collas G, McMell JW: Prolongation of retinal mean circulation time in diabetes. Arch Ophthalmol 1982, 100: 764-8.

26 Sinclair SH, Grunwald JE, Riva CE, Braunstein SN, Nicholls CW, Schwartz SS: Retinal vascular autoregulation in diabetes mellitus. Ophthalmology 1982, 89: 748-50. 